\title{
The Influence of Fence on Body Mass and Population Dynamics of Plateau Pika
}

\author{
Wenjing Li ${ }^{1,2}$ \\ ${ }^{1}$ Key Laboratory of Adaptation and Evolution of Plateau Biota, Northwest Institute of Plateau Biology, \\ Chinese Academy of Sciences, Xining, China \\ ${ }^{2}$ Scientific Research and Popularization Base of Qinghai-Tibet Plateau Biology, Qinghai Provincial Key Laboratory of \\ Animal Ecological Genomics, Xining, China \\ Email: lwenjing125@126.com
}

How to cite this paper: Li, W.J. (2020) The Influence of Fence on Body Mass and Population Dynamics of Plateau Pika. Open Journal of Ecology, 10, 729-736. https://doi.org/10.4236/oje.2020.1011044

Received: November 4, 2020

Accepted: November 27, 2020

Published: November 30, 2020

Copyright (c) 2020 by author(s) and Scientific Research Publishing Inc. This work is licensed under the Creative Commons Attribution International License (CC BY 4.0).

http://creativecommons.org/licenses/by/4.0/

\begin{abstract}
To determine the influence of the fence on plateau pika (Ochotona curzoniae), we measured the body mass, breeding status, population densities, using live-trapping and line-transect sampling in April and September 2006. In April, body mass of both male and female plateau pika inside of fence were significant higher than that outside of fence ( $q: \mathrm{F}=6.583, d f=1.20, p=$ $\left.0.019 ; \delta^{1} \mathrm{~F}=6.49, d f=1.17, p=0.021\right)$. The ratio of spermary drop of an adult male was also higher ( $92.31 \%$ vs $57.14 \%)$. In September, body mass of adult male in both study sites showed no significant difference $(\mathrm{F}=0.001, d f$ $=1.23, p=0.975)$, but were all significant higher than that of April $(\mathrm{F}=$ 121.713, $d f=1.22, p<0.001 ; \mathrm{F}=105.819, d f=1.20, p<0.001)$. In April, the population densities of both study sites showed on significant difference $(\mathrm{F}=$ 2.388, $d f=1.38, p=0.131$ ), but the population density inside of fence was much higher than that outside of fence $(\mathrm{F}=7.534, d f=1.38, p=0.009)$ in September. Our results show that the changes of quality and quantity of food that available to plateau pika in winter, can depress the range of reducing body mass of plateau pika, make breeding season ahead, and then promote the increase of population.
\end{abstract}

\section{Keywords}

Fence, Plateau Pikas, Ochotona curzoniae, Body Mass, Population Dynamics

\section{Introduction}

A lot of factors modulate mall mammal's population dynamics, and food condition plays an important role [1]. Variations of food conditions can make the 
montane vole (Microtus montanus Peale) change its primary breeding period, and then influence its population dynamic [1]. Food supply can increase the population density of prairie vole (Microtus ochrogaster Wagner) and root vole (Microtus oeconomus Pallas) and other small mammals [2] [3]. Food condition one of the most important factors that non-hibernation to go through the winter, high quality and quantity food can increase overwinter livability of adult individuals, and also can increase its litter size in the following breeding season [2]. And a study also indicated that lack of adequate food in the winter includes a major decline of vole populations in the absence of predators [4].

Plateau pika (Ochotona curzoniae Hodgson) is one of the dominant small mammals in the alpine meadow ecosystem of Qinghai-Tibet Plateau [5] [6]. It is aggravating the degradation of alpine meadow, for its high density in a degraded alpine meadow, digging activity and continuous grazing on the vegetation [7] [8] [9]. So people and the government used poisoning the pika, establish fence, sowing grass and so on to control the degradation of grassland in alpine meadow [10] [11]. Establish a fence is to prevent livestock grazing in the growing season. This changes vegetation condition in an alpine meadow, and then influence the quality and quantity of available food resources of small herbivore (like plateau pika) in cold and long winter, so its overwinter mission success rate, reproduction condition and population dynamics may changes. In order to determine the influence of establishing fences on plateau pika, we studied the body mass in spring, breeding status, the body mass of adult plateau pika in different seasons and the population dynamics of plateau pika in both areas of fences and no fences.

\section{Materials and Methods}

This study was conducted in northeast of Qinghai-Tibet plateau, about $30 \mathrm{~km}$ from the village of Senduo $\left(35^{\circ} 30^{\prime} \mathrm{N}, 101^{\circ} 10^{\prime} \mathrm{E}\right.$; Alt.: $\left.3400-3500 \mathrm{~m}\right)$, Guinan County of Qinghai Province, People's Republic of China in April and September of 2006. The climate of this area in Qinghai-Tibet plateau is dry and cool; average amount of precipitation is about $400 \mathrm{~mm}$, most rainfall occurs from June to August, and heavy snow-packs during winter are infrequent [12]. Vegetation in this area is typical Kobresia humilis (C. A. Mey. ex Trautv.) Serg. alpine meadow, most common monocotyledon are Kobresia sp., Elymus nutans Griseb., Stipa sp., and Carex sp.; and dicotyledon are Leontopodium nanum (Hook. f. et Thoms.) Hand.-Mazz., Gentiana sp., Potentilla sp., Oxytropis kansuensis Bunge, Thalictrum alpinum L., and Stellera chamaejasme L.

We selected two study sites according to the condition of fence and grazing. The study sites are not far away from each other, and are all flat, open and large enough (both about more than $20 \mathrm{hm}^{2}$ ). The details of the study sites are in $\mathrm{Ta}$ ble 1 .

In early April, most plants in the study sites are not sprout, so we measured the height and coverage percent of standing litter; and in late September most 
Table 1. Details of study sites.

\begin{tabular}{ccccc}
\hline Study site & Latitude & Longitude & Altitude (m) & Fence and grazing \\
\hline A & N: 3530331 & E: 10111298 & 3441 & $\begin{array}{c}\text { Without fence and grazing all year round, } \\
\text { heavily in August and September }\end{array}$ \\
B & N: 3530198 & E: 10112509 & 3473 & With fence around, only grazing in winter \\
\hline
\end{tabular}

plants are not dead, so height and coverage percent of vegetation were measured. In both study areas, 10 study plots of $50 \times 50 \mathrm{~cm}$ were selected in a line randomly. The height of vegetation was measured by ruler, and the coverage percent of monocotyledon and dicotyledon were measured using eye-free method. The total coverage percent of monocotyledon and dicotyledon was the coverage percent of vegetation. Walked transects [13] were used to measure the abundance of plateau pika between 10:00 and 11:00, which is the period when almost all plateau pikas are present on the surface [14]. An observer counted all plateau pikas in a $20-\mathrm{m}$ wide belt transect, with counts recorded for each of 10 contiguous $100-\mathrm{m}$ sections in each study site, then repeated it the following day. Population density (Pd) was calculated use formula as follows:

$$
\mathrm{Pd}=\frac{n}{a b} \times 10,000 \quad[15]
$$

In which $n$ is the number of plateau pika in each section, and a is the length of each section, $b$ is the width of belt transect. In this study, a equals $100 \mathrm{~m}$ and $\mathrm{b}$ is $20 \mathrm{~m}$.

All pikas were trapped in a core area of each study site using live-trap method. Make the record of sex, age, breeding status and body mass of all the plateau pikas which were trapped. Then left the pikas in the exact position where they were trapped. No pika was inactive during the trapping.

Average height of vegetation, coverage percent of vegetation, monocotyledon and dicotyledon, population density and body mass are all normal numerical value, so we used one-way ANOVA to test the difference between each study site. For spermary drop condition of plateau is non-numerical value, Chi-Squre Test was used to test its difference.

\section{Results}

In early April, most of the plants in the study area are not sprout, and most of the available food of pika is standing litter. The average height of standing litter in area $\mathrm{B}$ was significant higher than that of area $\mathrm{A}$ (Figure $1(\mathrm{a}) ; \mathrm{F}=6.657, d f=$ $1.19, p=0.019$; one-way ANOVA) Figure 1(a); and the same result was found on the coverage of standing dicotyledon (Figure 1(d); F = 7.579, $d f=1.19, p=$ 0.013; one-way ANOVA); coverage percent of standing litters and standing monocotyledon in area $\mathrm{B}$ were much higher than that of area $\mathrm{A}$, but with no significant difference (Figure 1(b), Figure 1(c); $\mathrm{F}=1.706, d f=1.19, p=0.203 ; \mathrm{F}=$ $0.379, d f=1.19, p=0.546$; one-way ANOVA). In September, average height and coverage percent of vegetation in area $\mathrm{B}$ were highly significant higher than that 
of area B (Figure 1(a), Figure 1(b); $\mathrm{F}=13.696, d f=1.19, p=0.002 ; \mathrm{F}=12.088$, $d f=1.19, p=0.003$; one-way ANOVA). Coverage percent of monocotyledon of area $A$ was lower than that of area $B$, but without significant difference (Figure 1 (c); $\mathrm{F}=2.62, d f=1.19, p=0.123$; one-way ANOVA).

In early April, body mass of both male and female adult pikas of area A were significant lower than that of area $\mathrm{B}$ (Figure 2; $+\mathrm{F}=6.583, d f=1.20, p=0.019$; $\delta: \mathrm{F}=6.49, d f=1.17, p=0.021$; one-way ANOVA). In September, average body mass of adult female pikas was almost the same in two areas (Figure 3; $\mathrm{F}=$ $0.001, d f=1.23, p=0.975$; one-way ANOVA). Compare to April, body mass of adult female of both areas increased highly significantly (Figure 3; A:F = 121.713,
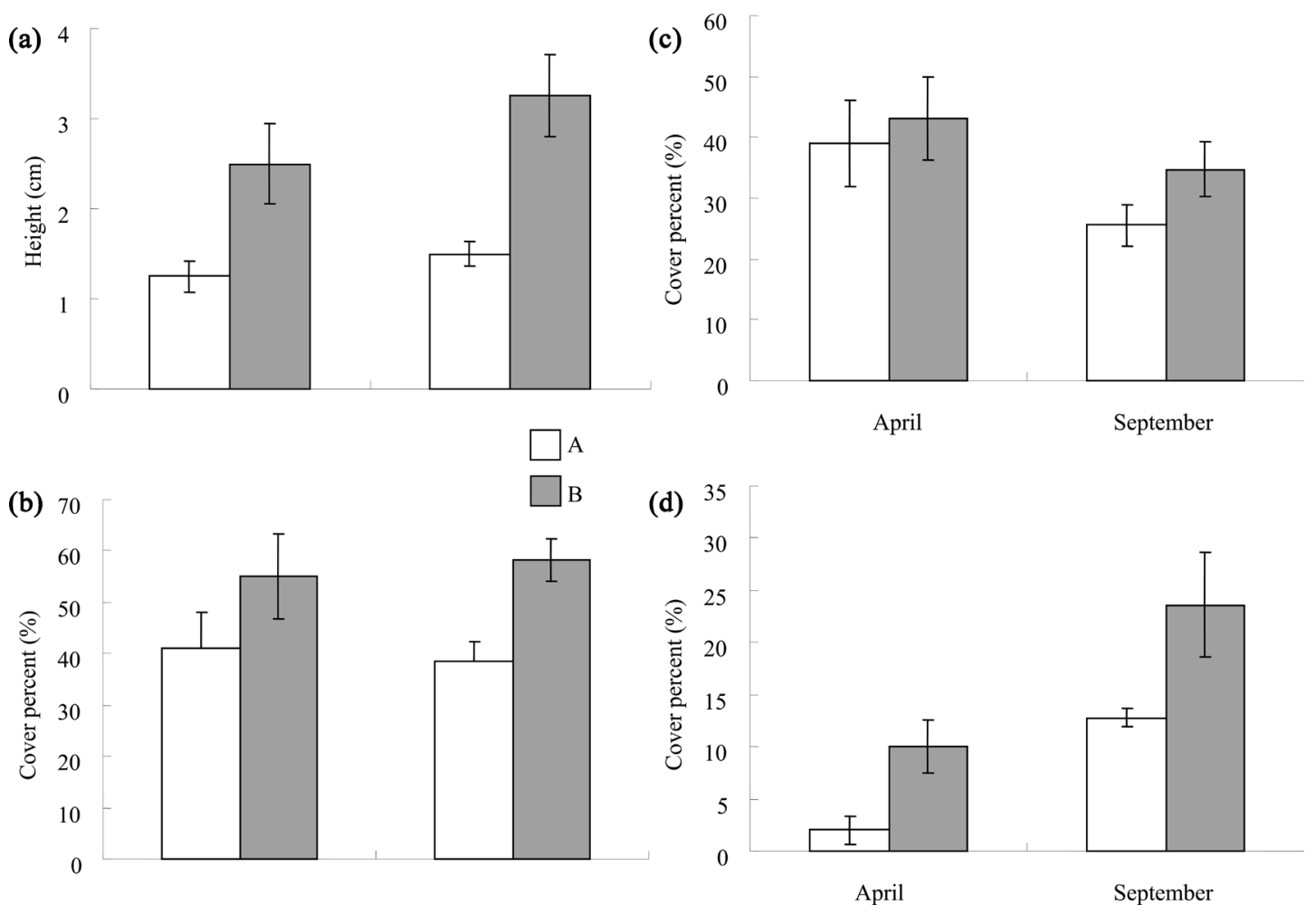

Figure 1. Average heights of vegetation, total cover percent, cover percent of monocotyledon and dicotyledon of different study areas in April and September. (a) Average heights of vegetation; (b) Total cover percent; (c) Cover percent of monocotyledon; (d) Cover percent of dicotyledon.

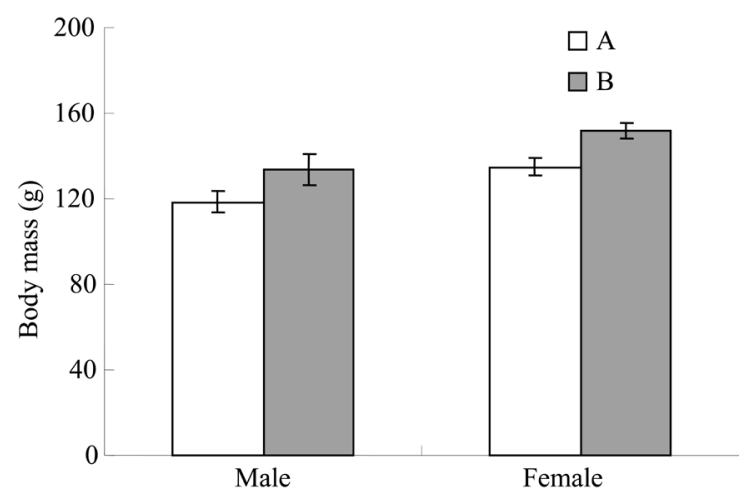

Figure 2. Weight of plateau pika of different study sites in April. 
$d f=1.22, p<0.001 ; \mathrm{B}: \mathrm{F}=105.819, d f=1.20, p<0.001$; one-way ANOVA). Because we did not trap enough adult male and sub-adult pikas, so the difference of body mass of adult male and sub-adult pikas was not compared in September.

During the study period in April, the ratio of spermary drop of adult male were not the same (A: $57.14 \%$ vs B: $92.31 \%$ ): we trapped 7 adult male in area A, and 4 of these spermary dropped, in area B was 12 and 11. But the drop of spermary in two areas showed no significant difference $\left(\chi^{2}=1.433, d f=1, p=0.231\right.$; Chi-Square Tests).

Population density of pika was much higher in September than that in April (Figure 4). Population densities of pika in area A were much higher than those of area $\mathrm{B}$ in April, and without significant difference $(\mathrm{F}=2.388, d f=1.38, p=$ 0.131; one-way ANOVA), but in September, population density of pika was significant lower than those of area $\mathrm{B}(\mathrm{F}=7.534, d f=1.38, p=0.009$; one-way ANOVA).

\section{Discussion}

Average height and coverage percent of vegetation were increased inside of fence (Figure 1), because the grazing of livestock in plant's growing season was limited. And this can give more available food resources for herbivore, specifically

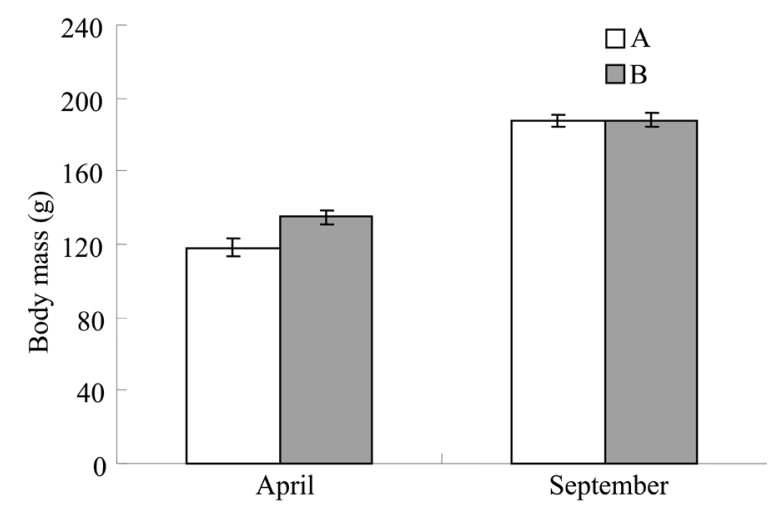

Figure 3. Weight of adult female plateau pika of different study sties in April and September.

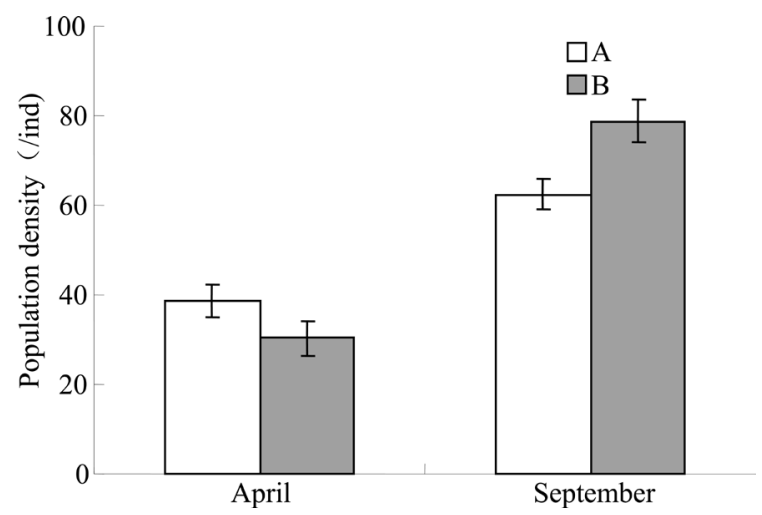

Figure 4. Population densities of plateau pika of different study sties in April and September. 
good conditions for small non-hibernate mammal in winter.

Body mass of adult plateau pika in livestock grazing all-year round area (A) was significant lower than that of area with fence where livestock only grazing in winter (B) (Figure 2), and the probable reason is that livestock's grazing in the growing season limited the growth of plant, the productivity of those areas decrease, the quality and quantity of food resource for plateau pika in winter and early spring decrease, and the pika did not get enough food. Compared to area (B) livestock grazing only in winter, in livestock grazing all-year round area (A), the difference between the coverage percent of standing litters and monocotyledon were not significant, but the coverage percent of standing dicotyledon showed significant decrease (Figure 1). The ratio of dicotyledon in plateau pika's food resource is much higher in the winter and spring [16], so monocotyledon in livestock grazing all-year round area is less than area livestock grazing only in winter, maybe is one of the reasons body mass of plateau pika is much lower in this area.

Body mass of adult female plateau pika in two study areas was almost the same in September (Figure 3), and the possible reason was that in the growing season plateau pika's food resource is adequate and rich in nutrition. And the day also was much longer, they have enough time for looking for food, so the food was not a factor that limit its growth. Compared to April, adult female plateau pika's body mass increased significantly in September, so the pika's body mass had seasonal changes, and pika can increase its body mass to through the shortage of food resource and extreme environment in winter. And this result was not accordant with the result of body mass of plateau pika has no seasonal changes in the library [17], we thought that in the library the plateau pika did not faced with the shortage of food as it in the field, so the connatural body mass change in the natural environment changed in the library. The increase in body mass, was beatification for plateau pika to through the long period of winter, is an adaptation to the extreme environment of the Qinghai-Tibet Plateau.

In the same time, the ratio of spermary drop of adult male in area with fence, and it meant the pika begins reproduction much earlier there, so did the female. There was no significant difference between the ratios of spermary drop of adult male in the study areas. Maybe sample size was not enough was the reason. Population density of plateau pika in area with fence was lower than that of area without fence in April, but the result was contrary, it indicated that in area with fence the ratio of population increase was much higher, changes of food conditions in winter can promote its reproduction, made its population increased much more quickly. This maybe also was one of the probable reasons that the population of plateau pika increased quickly after poisoning. A study in Naqu of Tibet also showed similar results [13].

\section{Conclusion}

Construction of fences and the following changes of livestock management make 
the cover percent and average height of vegetation changed, increases the quality and quantity of food available to plateau pika in winter. Changes of quality and quantity of food that available to plateau pika in winter can depress the range of reducing body mass of plateau pika, make breeding season ahead, and then promote the increase of population.

\section{Acknowledgements}

This work was supported by the Applied Basic Research Programs of Qinghai Province (2017-ZJ-714) and CAS “Light of West China” Program.

\section{Conflicts of Interest}

The author declares no conflicts of interest regarding the publication of this paper.

\section{References}

[1] Negus, N.C., Berger, P.J. and Forslund, L.G. (1977) Reproductive Strategy of Microtus montanus. Journal of Mammalogy, 58, 347-353. https://doi.org/10.2307/1379333

[2] Cole, F.R. and Batzli, G.O. (1978) Influence of Supplemental Feeding on a Vole Population. Journal of Mammalogy, 59, 809-819. https://doi.org/10.2307/1380145

[3] Nie, H.Y. and Liu, J.K. (2005) Regulation of Root Vole Population Dynamics by Food Supply and Predation: A Two-Factor Experiment. Oikos, 109, 387-395. https://doi.org/10.1111/j.0030-1299.2005.13330.x

[4] Huitu, O., Koivula, M., Korpimäki, E., Klemola, T. and Norrdahl, K. (2003) Winter Food Supply Limits Growth of Northern Vole Populations in the Absence of Predation. Ecology, 84, 2108-2118. https://doi.org/10.1890/02-0040

[5] Liu, J.K., Liang, J.R., Zhou, X.M. and Li, J.H. (1982) Rodent Community and Number in the Region of the Research Station of Alpine Meadow Ecosystem. In: Xia, W.P., Ed., Alpine Meadow Ecosystem I, Gansu People's Publishing House, Lanzhou, 34-43.

[6] Zong, H., Fan, N.C., Yu, X.F. and Zhu, J.C. (1991) The Research on the Population Spatial Patterns of the Plateau Zokor (Myospalax fontanierii) and the Plateau Pika (Ochotona curzoniae) in the Alpine Meadow Ecosystem. Acta Ecologica Sinica, 11, 125-129.

[7] Liu, J.K., Zhang, Y.Z. and Xin, G.W. (1980) Relationship between Numbers and Degree of Harmfulness of the Plateau Pika. Acta Zoologica Sinica, 26, 378-385.

[8] Shi, Y.Z. (1983) The Influences of Range-Land Vegetation to the Density of Plateau (Ochotona curzoniae). Acta Theriologica Sinica, 3, 181-188.

[9] Liu, W., Wang, X., Zhou, L. and Zhou, H.K. (2003) Studies on Destruction, Prevention and Control of Plateau Pikas in Kobresia pygmaea Meadow. Acta Theriologica Sinica, 23, 214-219.

[10] Jing, Z.C., Fan, N.C., Zhou, W.Y. and Bian, J.H. (1991) Integrate Management of Grassland Rodent Pest in Panpo Area. Chinese Journal of Applied Ecology, 2, 73-80.

[11] Wang, Q.Y., Jing, Z.C. and Fan, N.C. (1996) The Dynamics of Pest Rodents and the Integrated Management of Rodents on Alpine Meadow. In: Wang, Z.W. and Zhang, 
Z.B., Eds., Theory and Practice of Rodent Pest Management, Science Press, Beijing, 206-228.

[12] Dobson, F.S., Smith, A.T. and Wang, X.G. (1998) Social and Ecological Influences on Dispersal and Philopatry in the Plateau Pika (Ochotona curzoniae). Behavioral Ecology, 9, 622-635. https://doi.org/10.1093/beheco/9.6.622

[13] Pech, R.P., Arthur, A.D., Zhang, Y.M. and Lin, H. (2007) Population Dynamics and Responses to Management of Plateau Pikas Ochotona curzoniae. Journal of Applied Ecology, 44, 615-624. https://doi.org/10.1111/j.1365-2664.2007.01287.x

[14] Zong, H. and Xia, W.P. (1987) Circadian Activity Rhythms of Plateau Pikas. Acta Theriologica Sinica, 7, 211-223.

[15] Merikalio, E. (1958) Finnish Birds: Their Distribution and Numbers. Fauna Fennica, 5, 1-181.

[16] Zhang, Y., Liu, W. and Wang, X.Y. (2005) A Preliminary Study of Caching Behavior of the Plateau Pika. Zoological Research, 26, 479-483.

[17] Wang, J.M., Zhang, Y.M. and Wang, D.H. (2006) Seasonal Thermogenesis and Body Mass Regulation in Plateau Pika (Ochotona curzoniae). Oecologia, 149, 373-382. https://doi.org/10.1007/s00442-006-0469-1 